\title{
Maneuvering Hydrodynamic Forces Acting on Manta-type UUV Using CFD
}

\author{
Seong-Eun Lee ${ }^{\circledR}$, Sung-Wook Lee $\circledast^{\oplus^{2}}$ and Jun-Young Bae $\circledast^{3}$ \\ ${ }^{1}$ Graduated Student Naval Architecture and Ocean Engineering, KMOU, Busan, Korea \\ ${ }^{2}$ Professor, Naval Architecture and Ocean Engineering, KMOU, Busan, Korea \\ ${ }^{3}$ Professor, Department of Automobile \& Mechanics, Dongju College, Busan, Korea
}

KEY WORDS: Manta-type, Unmanned underwater vehicles(UUV), Model test, Computational fluid dynamics(CFD), Manoeuvring hydrodynamic forces

\begin{abstract}
In this study, we investigate surge force, heave force, and pitch moment, which are vertical plane hydrodynamics acting on Manta-type unmanned underwater vehicles (UUVs), using a model test and computational fluid dynamics (CFD) simulation. Assessing the maneuvering hydrodynamic characteristic of an underwater glider in the initial design stage is crucial. Although a model test is the best approach for obtaining the maneuvering hydrodynamic derivatives for underwater vehicles, numerical methods, such as Reynolds averaged Navier-Stokes (RANS) equations, have been used owing to their efficiency in terms of time and cost. Therefore, we conducted an RANS-based CFD calculation and a model test for Manta-type UUVS. In addition, we conducted a validation study through a comparison with a model test conducted at a circular water channel (CWC) in Korea Maritime \& Ocean University Furthermore, two RANS solvers (Star-CCM+ and OpenFOAM) were used and compared. Finally, the maneuvering hydrodynamic forces obtained from the static drift and resistance tests for a Manta-type UUV were presented.
\end{abstract}

\section{Introduction}

In the past 20 years in South Korea, underwater vehicles - which can be used for various purposes, such as marine exploration and military use - have been actively researched (Bae and Sohn, 2009; Ko et al., 2013). Despite the emerging utilization of aquatic bodies, not much research data related to their varied linearities have been revealed, compared to the results published for various surface-piercing vessels.

In general, the estimation of maneuvering performance is an important factor in the initial design stage of surface vehicle development. The maneuvering performance can be predicted using the following two methods: captive model test and free-running model test. The prediction method using the free-running model test shows the closest results to the maneuvering performance of a vehicle; however, it is difficult to build a free-running system and conduct tests. Therefore, the maneuvering performance is mostly predicted by measuring the force and moment acting on the hull, using the captive model test. There is another prediction method, based on sea-trial data that have been researched and accumulated thus far. With the recent development of computer hardware, performance prediction through virtual captive model testing or virtual planar motion mechanism is being actively performed using computational fluid dynamics (CFD) simulation.

Conversely, applying the same method of predicting the performance of a surface vehicle for predicting the maneuvering performance of an underwater vehicle requires watertightness of the model, as the experiment for a captive model test is conducted under the free surface, which results in increased production cost and difficulties in preparing the test apparatus. The free-running model test conducted for an underwater vehicle is more difficult than that conducted for a surface vehicle; moreover, no previously reviewed or disclosed trial run data is available.

For this reason, CFD can be easily used for predicting the maneuvering performance of an underwater vehicle; in fact, this has been extensively researched (Singh et al., 2017; Cheon et al., 2018).

Therefore, this study aims to examine the hydrodynamic force acting on the forward and static drift motions of an underwater vehicle using CFD, based on Reynolds-averaged Navier-Stokes (RANS) equations.

Star-CCM+, a commercial software, and OpenFOAM, an open-

Received 2 March 2020, revised 22 June 2020, accepted 25 June 2020

Corresponding author Sung-Wook Lee: +82-51-410-4303, swlee@kmou.ac.kr

(c) 2020, The Korean Society of Ocean Engineers

This is an open access article distributed under the terms of the creative commons attribution non-commercial license (http://creativecommons.org/licenses/by-nc/4.0) which permits unrestricted non-commercial use, distribution, and reproduction in any medium, provided the original work is properly cited. 
source tool kit, are used as the CFD solvers. In addition, to examine the effectiveness of the CFD analysis results and usefulness of CFD, the obtained results are compared with those obtained using the captive model tests conducted by Bae and Sohn (2009) in a circular water channel (CWC) for the same linear underwater vehicle. Meanwhile, to verify the previously obtained results, retests are conducted using the same unmanned underwater vehicle (UUV) model, to compare and review the final results.

\section{Experimental and Numerical Analysis Conditions}

We conducted a resistance test and static drift test to study the maneuvering hydrodynamic forces acting on a Manta-type UUV, through an experiment and a CFD analysis. Table 1 shows the maneuvering hydrodynamic derivatives obtained from each test.

Table 1 Hydrodynamic derivatives obtained from each test

\begin{tabular}{|c|c|c|}
\hline \multicolumn{2}{|c|}{ Item } & $\begin{array}{c}\text { Maneuvering } \\
\text { hydrodynamic derivative }\end{array}$ \\
\hline \multicolumn{2}{|c|}{ Resistance test } & $X_{u u}{ }^{\prime}$ \\
\hline \multirow{3}{*}{ Static drift test } & Surge & $X_{u u}{ }^{\prime}, X_{u w}{ }^{\prime}, X_{w w}{ }^{\prime}$ \\
\hline & Heave & $Z_{u u}{ }^{\prime}, Z_{u w}{ }^{\prime}, Z_{w}^{\prime}, Z_{w|w|}{ }^{\prime}$ \\
\hline & Pitch & $M_{u u}{ }^{\prime}, M_{u w}{ }^{\prime}, M_{w}{ }^{\prime}, M_{w|w|}{ }^{\prime}$ \\
\hline
\end{tabular}

\subsection{Geometric Specification of Manta-type UUV}

Among the underwater vehicles, a Manta-type UUV model, which has already been studied, was selected as the target vehicle for this

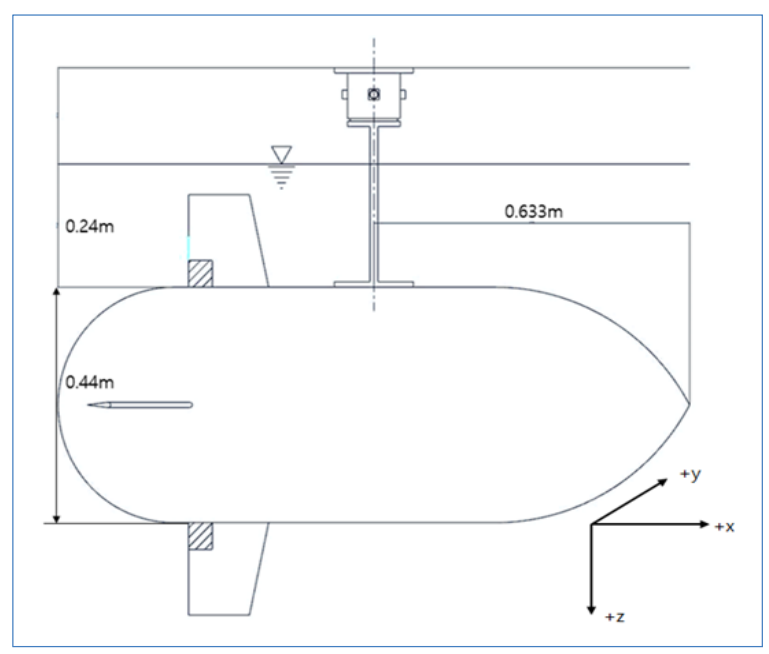

(a) Horizontal plan

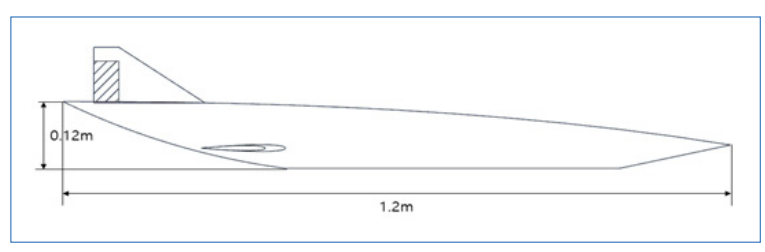

(b) Manta UUV profile

Fig. 1 Drawings of Manta-type UUV

Table 2 Principal dimensions of Manta-type UUV

\begin{tabular}{ccc}
\hline \multicolumn{3}{c}{ Manta UUV \& Model principal } \\
\hline Item & Manta & model \\
\hline Length (m) & 12 & 1.2 \\
Breadth (m) & 4.4 & 0.44 \\
Height (m) & 1.2 & 0.12 \\
Centroid (m) (from nose) & 6.333 & 0.6333 \\
Scale ratio & & 0.1 \\
\hline
\end{tabular}

study. Fig. 1 shows the shape of the Manta model, and Table 2 lists its dimensions.

\subsection{Experimental Conditions}

The experiment was conducted in a CWC at Korea Maritime and Ocean University, whose specifications are listed in Table 3. As shown in Fig. 2, the hydrodynamic force acting on the Manta-type UUV was measured for $3 \mathrm{~min}$, twice for each experimental condition, using a three-component force transducer with capacities of $\pm 50 \mathrm{~N}$ for force $\left(F_{x}, F_{y}\right)$ and $\pm 10 \mathrm{~N}-\mathrm{m}$ for moment $\left(M_{z}\right)$.

Table 3 CWC details

\begin{tabular}{c}
\hline CWC details \\
\hline Type 2 Impeller vertical type \\
(OV2-60B)
\end{tabular}

Dimensions whole body L : $12.5 \mathrm{~m}, \mathrm{~W}: 2.2 \mathrm{~m}, \mathrm{H}: 5.2 \mathrm{~m}$ Dimensions measuring section $\mathrm{L}: 5 \mathrm{~m}, \mathrm{~W}: 1.8 \mathrm{~m}, \mathrm{H}: 1.2 \mathrm{~m}$

$$
\begin{gathered}
\text { Water capacity } \\
\text { Performance }
\end{gathered}
$$

Driving system Impeller motor

Date MFD

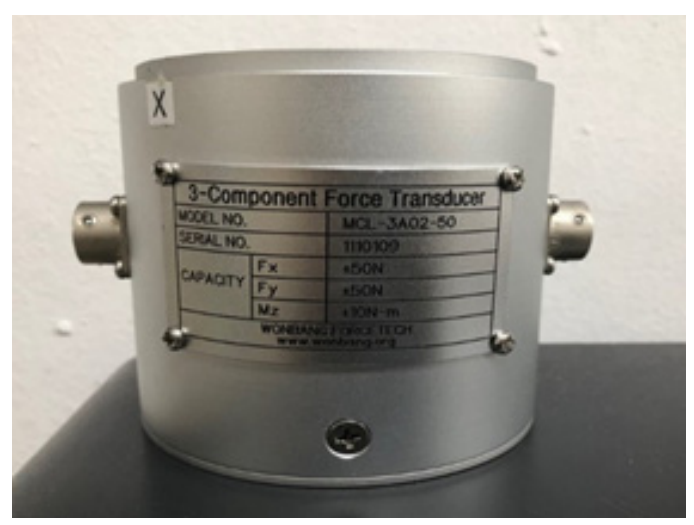

Fig. 2 Three-component force transducer

\subsubsection{Resistance test}

In this study, the same velocity as that used for the Manta UUV in the model test conducted by Bae and Sohn (2009) was selected using the Reynolds number, whose details are presented in Table 4. In the subsequent results, $\mathrm{Vm}$ denotes the velocity used in each test and the CFD analysis. 
Table 4 Conditions for resistance test

Velocity $(\mathrm{m} / \mathrm{s}) \quad 0.32,0.4,0.5,0.6$

\subsubsection{Static drift test}

A static drift test was conducted to experimentally measure the surge force, heave force, and pitch moment, which are the vertical hydrodynamic damping forces acting on the model. Owing to the limited capacity of the three-component force transducer, the elevation test was conducted only at 0.32 and $0.4 \mathrm{~m} / \mathrm{s}$ under the conditions listed in Table 5. As shown in Fig. 3, the velocity was measured at measurement points $15 \mathrm{~cm}$ away from the center, left, and right of the hull, to confirm if the velocity in the circular water tank was uniformly distributed during the static drift test.

Table 5 Conditions for static drift test

\begin{tabular}{cc}
\hline Velocity $(\mathrm{m} / \mathrm{s})$ & Drift angle $\left(^{\circ}\right)$ \\
\hline 0.32 & $\pm 0,3,6,9,12,15,20$ \\
0.4 & $\pm 0,5,10,15,20$ \\
\hline
\end{tabular}

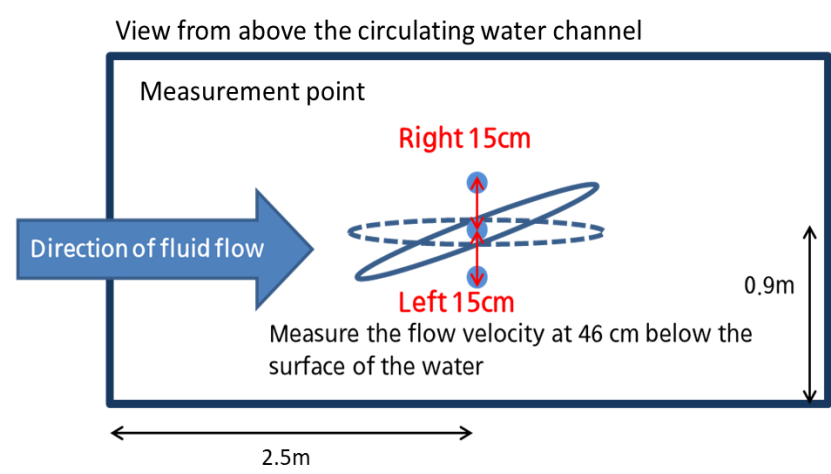

Fig. 3 Velocity calibration measuring point

\subsection{Numerical Analysis Conditions}

The CFD solver mainly used in this study was Star-CCM+, which performed numerical analysis to understand the hydrodynamic forces and phenomena acting on the underwater vehicle, as mentioned in the Introduction. To confirm the reliability of the numerical analysis result, according to the difference between the Star-CCM+ solver and interFOAM, which is the transient-flow solver of OpenFOAM, a numerical analysis was conducted using the same grid mesh and numerical technique as those used for OpenFOAM under certain conditions in Table 7.

The size of the computational domain used for the CFD analysis was set similarly to the measuring points set for the CWC, as shown in Fig. 4. The volume-of-fluid technique was used for the governing equation of the multiphase flow, and $k-\omega$ was used as the turbulence model. Table 6 shows the details of the numerical techniques applied to the analysis.

As shown In the table, the analysis time was set to $50 \mathrm{~s}$ to allow the forces acting on the vehicle to converge sufficiently. Fig. 5 presents the results obtained for the time-step sensitivity test, indicating the
Table 6 Conditions for CFD (Star-CCM+ \& OpenFOAM)

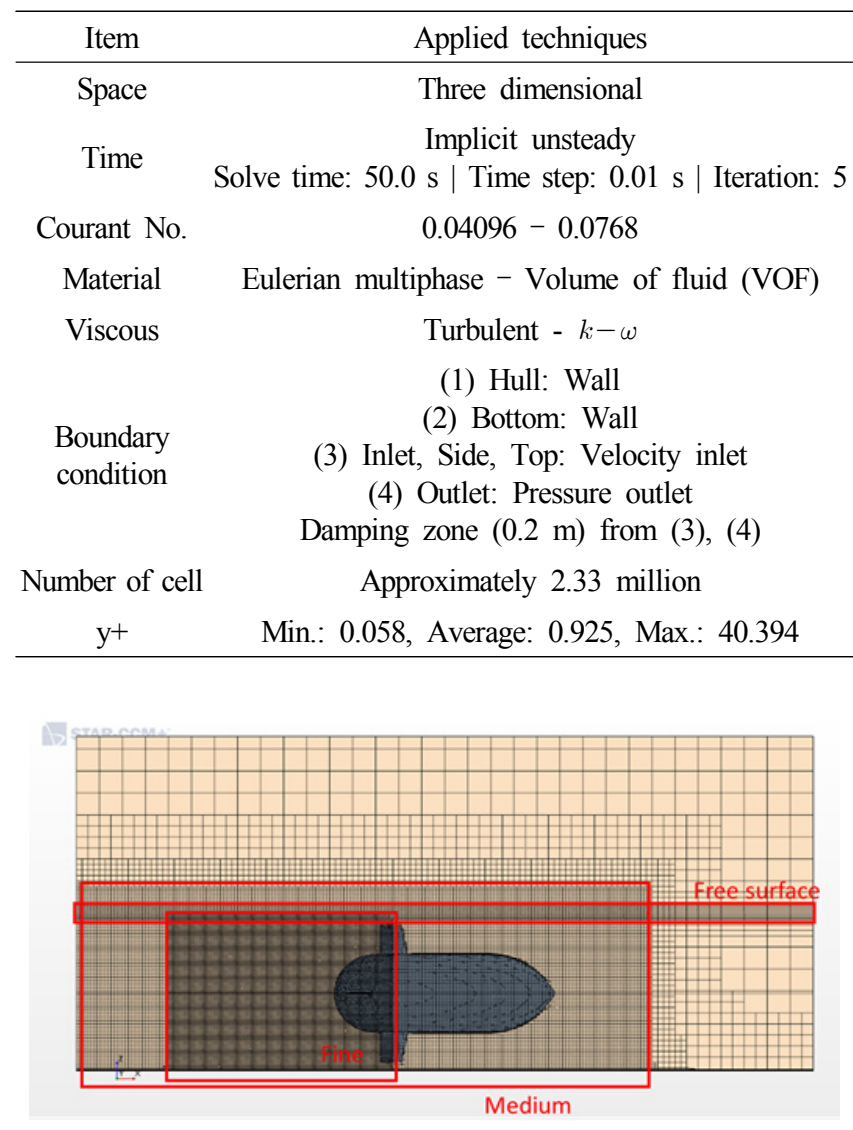

(a) Refinement grid mesh in CFD

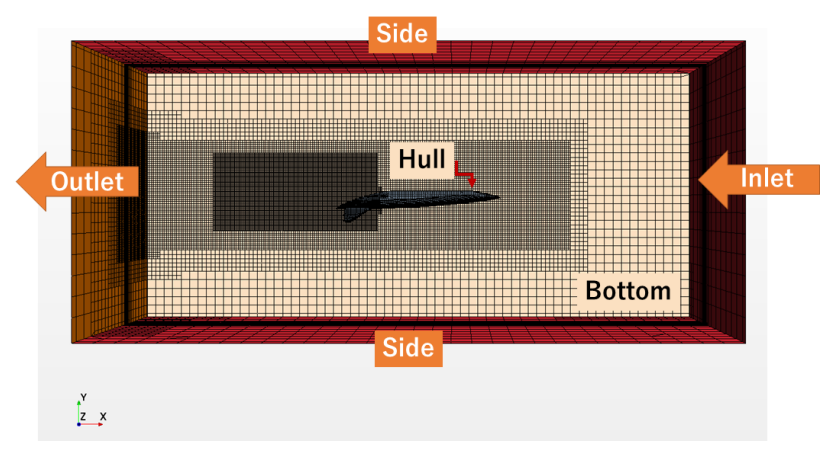

(b) Set boundary condition in CFD

Fig. 4 Grid system in CFD

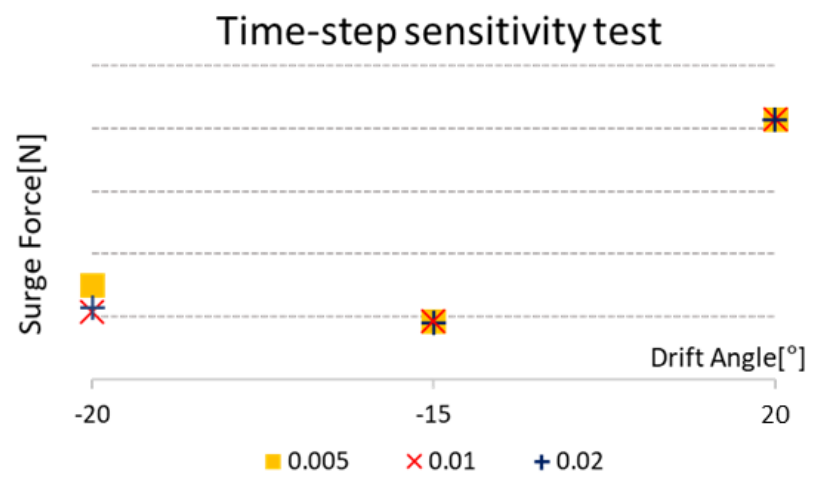

Fig. 5 Results obtained for time-step sensitivity test 
surge force at a specific drift angle. According to the results, there were slight differences in the analysis results at a drift angle of $-20^{\circ}$. However, there was no difficulty in setting the time step to $0.01 \mathrm{~s}$, considering the efficiency of the calculation. When assuming the computational domain to be a CWC, there was no significant difference from the results obtained with the boundary conditions set to "Wall" for the side parts, referred to as the side walls. Therefore, for convenience of calculation, the velocity inlet boundary conditions, assuming far-field boundary conditions, were used.

\section{Comparison of Experimental and Numerical Results}

\subsection{Comparison of Resistance Test Results}

Fig. 6 shows the experimental and CFD analysis results obtained for the resistance at different velocities. Here, the vertical axis indicates the resistance coefficient $\left(X^{\prime}{ }_{u u}\right)$, which is a dimensionless value of the measured resistance of $0.5 \rho L^{2} U^{2}$ (where $\rho$ : fluid density, $L$ : length of the Manta-type UUV, and $U$ : fluid velocity).

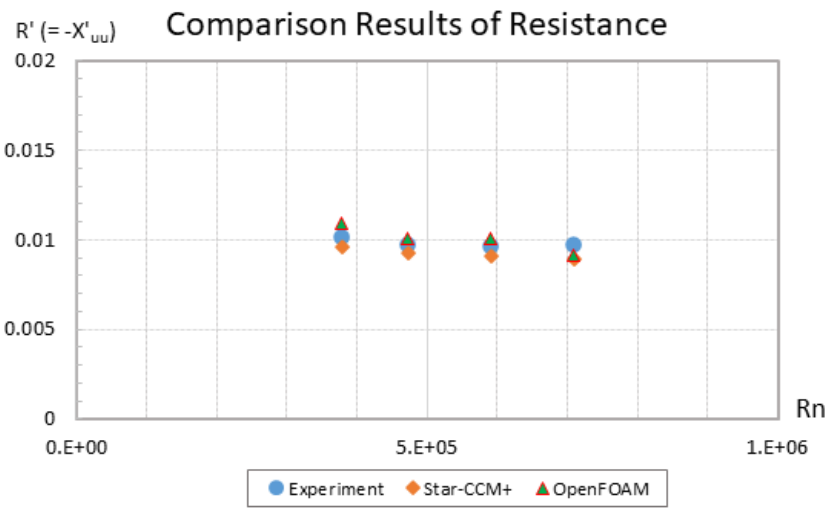

Fig. 6 Comparison of results obtained for resistance acting on Manta-type UUV at different velocities

First, the calculation results obtained for Star-CCM+ indicated smaller resistance values than those indicated by the model test results, while those obtained for OpenFOAM had larger values, except for 0.6 $\mathrm{m} / \mathrm{s}$. This suggests that the $k-\omega$ SST turbulence model of OpenFOAM used in this study tends to be estimated with a smaller force as the velocity increases, which needs to be studied further. Considering that this study aims to show the usefulness of CFD analysis in the motion of underwater vehicles, rather than its advancement, the obtained result is reliable.

\subsection{Comparison of Static Drift Test Analysis}

As described above, the CFD solver mainly used in this study was Star-CCM+ and a numerical analysis was performed using OpenFOAM under the calculation conditions listed in Table 7. For reference, all CFD results presented in 3.2.1-3.2.3 were analyzed prior to performing the model test, which was used as a reference to verify the CFD analysis results.

In addition, the force and moment were non-dimensionalized as 0.5 $\rho L^{2} U^{2}$ and $0.5 \rho L^{2} U^{2}$, respectively, to review the results.
Table 7 Static drift test and CFD calculation conditions

\begin{tabular}{|c|c|c|c|}
\hline $\begin{array}{l}\text { Velocity } \\
(\mathrm{m} / \mathrm{s})\end{array}$ & $\begin{array}{l}\text { Experiment } \\
\left({ }^{\circ}\right)\end{array}$ & $\begin{array}{c}\text { CFD } \\
(\mathrm{Star}-\mathrm{CCM}+) \\
\left({ }^{\circ}\right)\end{array}$ & $\begin{array}{c}\text { CFD } \\
\text { (OpenFOAM) } \\
\left({ }^{\circ}\right)\end{array}$ \\
\hline 0.32 & $\begin{array}{c} \pm 0,3,6,9 \\
12,15,20\end{array}$ & $\begin{array}{c} \pm 0,3,9 \\
15,20\end{array}$ & N/A \\
\hline 0.4 & $\begin{array}{c} \pm 0,5,10 \\
15,20\end{array}$ & $\begin{array}{c} \pm 0,5,10 \\
15,20\end{array}$ & $\pm 0,5,10$ \\
\hline
\end{tabular}

\subsubsection{Surge force}

Figs. 7 and 8 show the dimensionless results obtained for the model test and CFD calculation for the surge force (force acting on the model vehicle in the straight direction) according to the change in the drift angle of the Manta-type UUV at 0.32 and $0.4 \mathrm{~m} / \mathrm{s}$ velocities, respectively. These velocities result from the curve fitting conducted using the least-squares method and Eq. (1). The relevant hydrodynamic derivatives obtained from the results are shown in Tables 8 and 9.

As shown in Fig. 8, the surge force was temporarily reduced at a drift angle of $-5^{\circ}$ in the model test, whereas such phenomenon was not observed in CFD. It is believed that the flow at the small negative drift angle affected the overall surge force due to the change in the surge force acting on the vertical wing of the underwater vehicle. This change may have been detected in the model test, but not in the CFD.

This is considered to be a limitation of the CFD analysis conducted using the RANS equation, and for the purpose of this study, the analysis for a more specific cause identification has not been conducted. Overall, in Fig. 8, the experimental and CFD results tend to be similar, except at the drift angle of $-5^{\circ}$, as described above.

$$
X^{\prime}=X_{u u}{ }^{\prime} u^{\prime 2}+X_{u w}{ }^{\prime} u^{\prime} w^{\prime}+X_{w w}{ }^{\prime} w^{\prime 2}
$$

A detailed analysis of Figs. 7 and 8 shows that as the drift angle increases in the positive $(+)$ direction, the surge force decreases; in

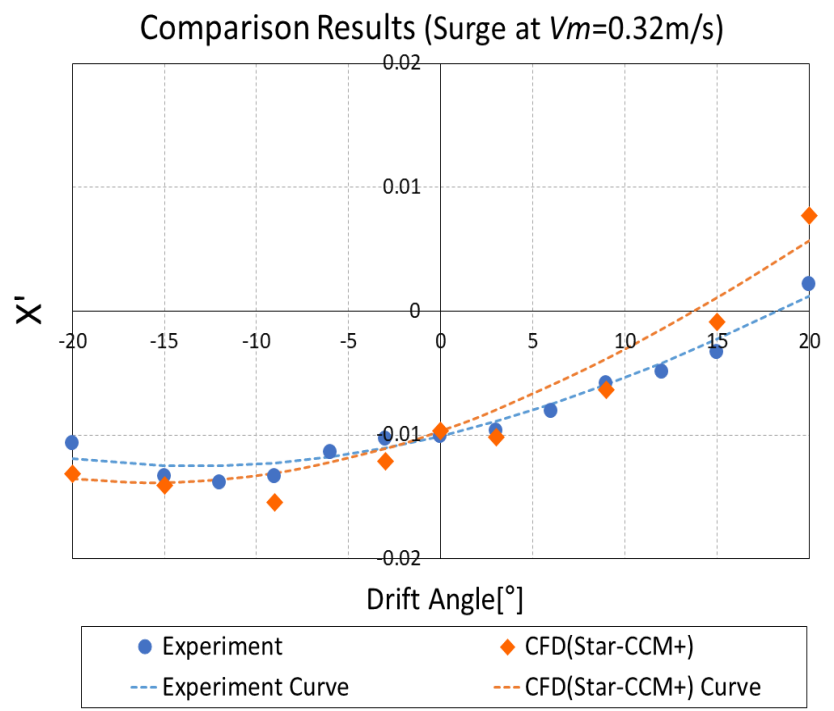

Fig. 7 Comparison of surge force acting on Manta-type UUV between the experiment and CFD calculation at $V m=0.32 \mathrm{~m} / \mathrm{s}$ 
Table 8 Comparison of hydrodynamic derivatives obtained from the surge force acting on Manta-type UUV between the experiment and CFD calculation at $V m=0.32 \mathrm{~m} / \mathrm{s}$

\begin{tabular}{ccc}
\hline $\begin{array}{c}\text { Hydrodynamic } \\
\text { derivatives }\end{array}$ & Experiment & CFD (Star-CCM+) \\
\hline$X_{u u}{ }^{\prime}$ & -0.0101 & -0.0096 \\
$X_{u w}{ }^{\prime}$ & 0.0204 & 0.0299 \\
$X_{w w}{ }^{\prime}$ & 0.0305 & 0.0394 \\
\hline
\end{tabular}

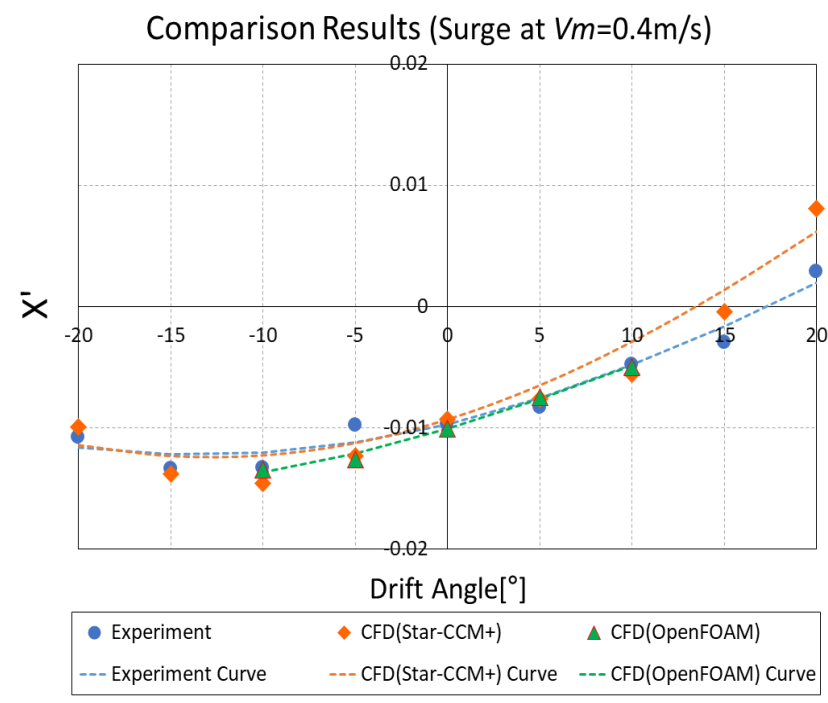

Fig. 8 Comparison of surge force acting on Manta-type UUV between the experiment and CFD calculation at $V m=0.4 \mathrm{~m} / \mathrm{s}$

Table 9 Comparison of hydrodynamic derivatives obtained from the surge force acting on Manta-type UUV between the experiment and CFD calculation at $\mathrm{Vm}=0.4 \mathrm{~m} / \mathrm{s}$

\begin{tabular}{cccc}
\hline $\begin{array}{c}\text { Hydrodynamic } \\
\text { derivatives }\end{array}$ & Experiment & $\begin{array}{c}\text { CFD } \\
(\text { Star-CCM+) }\end{array}$ & $\begin{array}{c}\text { CFD } \\
\text { (OpenFOAM) }\end{array}$ \\
\hline$X_{u u}{ }^{\prime}$ & -0.0097 & -0.0093 & -0.0101 \\
$X_{u w}{ }^{\prime}$ & 0.0211 & 0.0273 & 0.0250 \\
$X_{w w}{ }^{\prime}$ & 0.0319 & 0.0478 & 0.0157 \\
\hline
\end{tabular}

contrast, when it increases in the negative (-) direction, the surge force increases and then decreases.

An analysis of the maneuvering hydrodynamic derivatives, obtained from the experimental and CFD calculation results listed in Tables 8 and 9 , indicates that although the hydrodynamic derivatives obtained from the Star-CCM+ calculation results slightly differ from those obtained from the experimental results, they are still quite similar. This indicates that there are some quantitative differences because the physical quantity of the surge force itself has a small value, but they are in good agreement when viewed qualitatively. As the maneuvering hydrodynamic derivatives obtained from the OpenFOAM results listed in Table 9 are calculated only under some conditions, the result for $X_{w w}{ }^{\prime}$ is significantly different from the experimental and Star-CCM+ results, but those for $X_{u u}{ }^{\prime}$ and $X_{u w}{ }^{\prime}$ are similar, indicating that the results are in good agreement.

An the analysis of the tendency of the surge force according to the drift angle, conducted only using the model test results, indicated that when the drift angle increased in the positive direction in Fig. 10(b), a counter-current was generated in the back due to the sharply bent shape of part (3) and a force in the opposite direction to the surge force was applied. Similarly, when the drift angle increased in the negative direction, the force in the opposite direction to the surge force acted at a diagonal angle as separation occurred near the vertical wing of part (4).

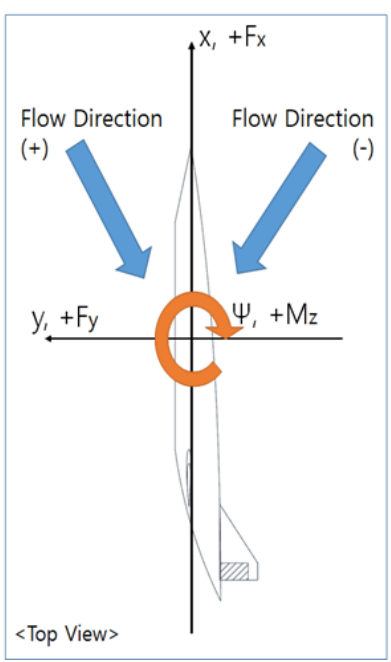

(a) Coordinate system

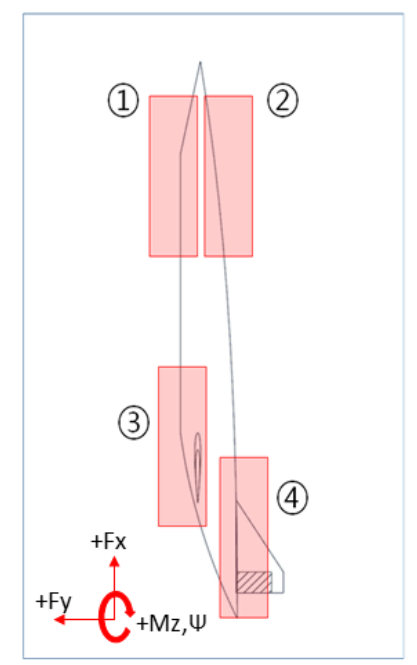

(b) Model features
Fig. 10 Coordinate system of static drift test and UUV model features

TOTAL

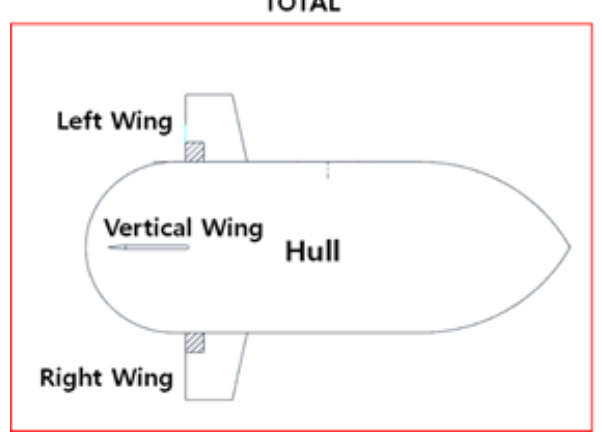

Fig. 11 Components of Manta-type UUV

Table 10 Comparison of static drift test surge force acting on Manta-type UUV's each component at $V m=0.32 \mathrm{~m} / \mathrm{s}$

\begin{tabular}{ccc}
\hline Component & $F x(\mathrm{~N})\left(\Psi=20^{\circ}\right)$ & $F x(\mathrm{~N})\left(\Psi=-20^{\circ}\right)$ \\
\hline Hull & 0.780 & -0.783 \\
Left wing & -0.050 & -0.041 \\
Right wing & -0.048 & -0.029 \\
Vertical wing & -0.114 & -0.118 \\
Total & 0.568 & -0.973 \\
\hline
\end{tabular}




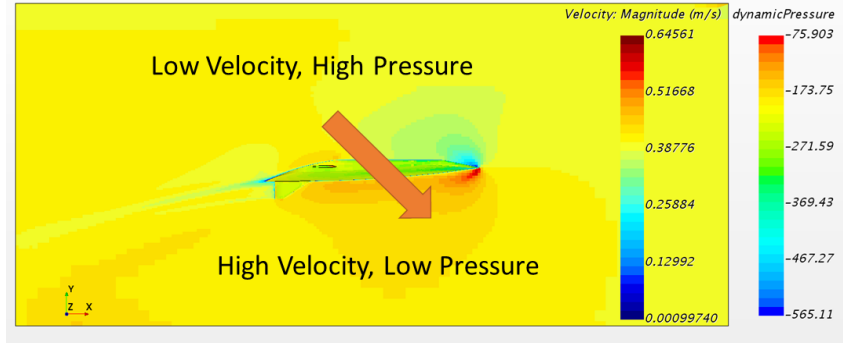

(a) Top view in CFD $\left(\mathrm{Vm}=0.32 \mathrm{~m} / \mathrm{s}, \Psi=20^{\circ}\right)$

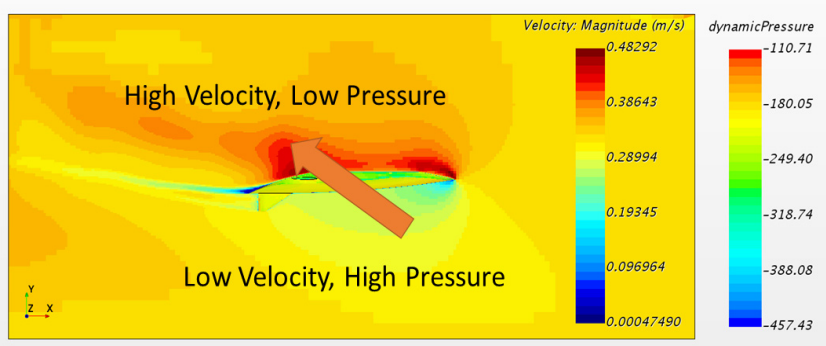

(b) Top view in CFD $\left(\mathrm{Vm}=0.32 \mathrm{~m} / \mathrm{s}, \Psi=-20^{\circ}\right)$

Fig. 12 Flow field of $\Psi=20^{\circ} \&-20^{\circ}$ in CFD

To understand the exact trend when calculating using CFD, the Manta-type UUV was divided into the hull and wing parts, as shown in Fig. 11, to examine the hydrodynamic forces acting on each part. Table 10 shows the numerical values for the calculation results obtained at drift angles of $+20^{\circ}$ and $-20^{\circ}$. Fig. 12 shows the flow field around the hull at drift angles of $+20^{\circ}$ and $-20^{\circ}$, where the colors of the object surface indicate the pressure distribution acting on the hull. As shown in Table 10, the surge force (force acting in the straight direction) acting on the horizontal wings (left and right wings) and vertical wing is similar regardless of the drift angle. However, the surge force (force acting in the straight direction) acting on the hull shows a significant difference. At $+20^{\circ}$, a faster flow apparently occurs at the bow side, and a force, such as thrust, is generated through the pressure difference, as shown in Fig. 12(a); at $-20^{\circ}$, the opposite phenomenon occurs, increasing the resistance as shown in Fig. 12(b). However, as shown in the comparison of the two flow field plots in Fig. 12, because a more complex flow phenomenon occurs and the force in the opposite direction of the surge force acts on the UUV due the counter-current at a drift angle of $-20^{\circ}$, the resistance tends to decrease when the drift angle increases in the negative direction.

Due to the limitations of the experimental facility, the experiment was conducted with the horizontal wings of the UUV placed near the free surface and bottom, and the CFD calculation was conducted in the same computational domain as that of the experiment. Table 10 shows almost the same results for the surge forces acting on the left wing close to the free water surface and the right wing close to the bottom, indicating that the effect of the free surface on the UUV is rather insufficient.

\subsubsection{Heave force}

Figs. 13 and 14 show the dimensionless results of the model test and CFD calculation for the heave force (force acting on the model vehicle in the transverse direction) according to the change in the drift angle of the Manta-type UUV at velocities of 0.32 and $0.4 \mathrm{~m} / \mathrm{s}$, respectively. These velocities are the curve fitting results obtained using the leastsquares method and Eq. (2). The relevant maneuvering hydrodynamic derivatives obtained from the results are shown in Tables 11 and 12 .

$$
Z^{\prime}=Z_{u u}{ }^{\prime} u^{\prime 2}+Z_{u w}{ }^{\prime} u^{\prime} w^{\prime}+Z_{w w}{ }^{\prime} w^{2}+Z_{w|w|}{ }^{\prime} w^{\prime 3}
$$

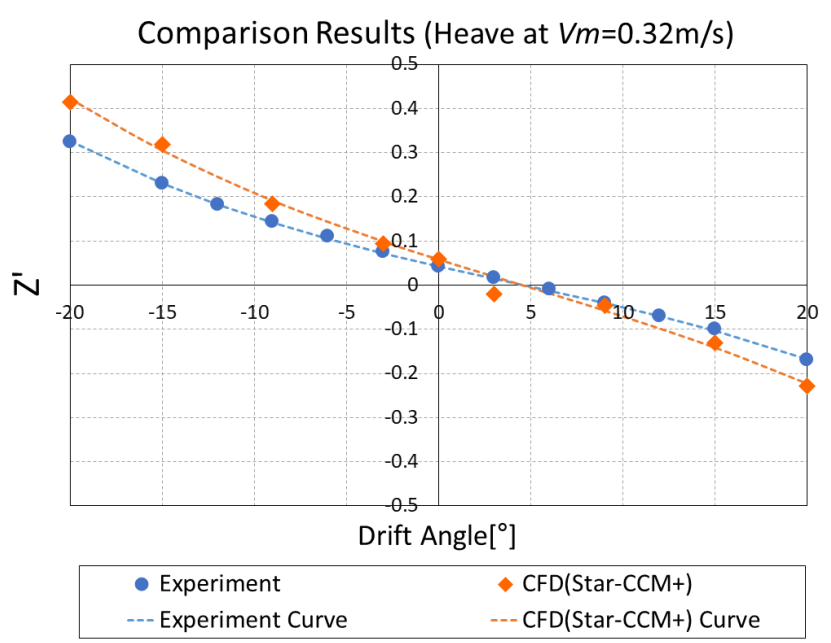

Fig. 13 Comparison of heave force acting on Manta-type UUV at $V m=0.32 \mathrm{~m} / \mathrm{s}$

Table 11 Comparison of hydrodynamic derivatives obtained from the heave force acting on Manta-type UUV between the experiment and CFD calculation at $V m=0.32 \mathrm{~m} / \mathrm{s}$

\begin{tabular}{ccc}
\hline $\begin{array}{c}\text { Hydrodynamic } \\
\text { derivatives }\end{array}$ & Experiment & CFD (Star-CCM+) \\
\hline$Z_{u u}{ }^{\prime}$ & 0.0430 & 0.0584 \\
$Z_{u w}{ }^{\prime}$ & 0.5417 & 0.7542 \\
$Z_{w w}{ }^{\prime}$ & 0.3509 & 0.4110 \\
$Z_{w|w|}{ }^{\prime}$ & 1.8038 & 1.9965 \\
\hline
\end{tabular}

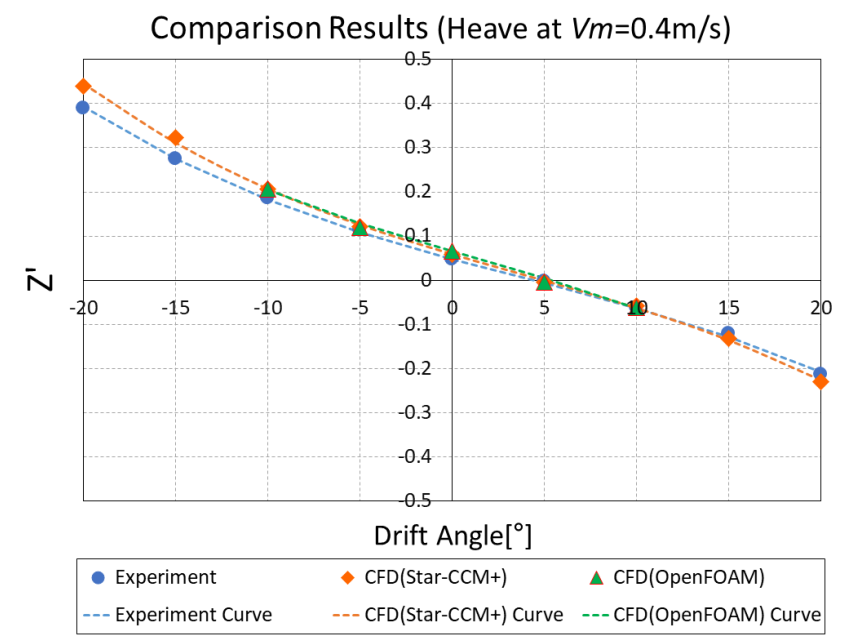

Fig. 14 Comparison of heave force acting on Manta-type UUV between the experiment and CFD calculation at $V m=0.4 \mathrm{~m} / \mathrm{s}$ 
Table 12 Comparison of hydrodynamic derivatives obtained from heave force acting on Manta-type UUV between the experiment and CFD calculation at $V m=0.4 \mathrm{~m} / \mathrm{s}$

\begin{tabular}{cccc}
\hline $\begin{array}{c}\text { Hydrodynamic } \\
\text { derivatives }\end{array}$ & Experiment & $\begin{array}{c}\text { CFD } \\
\text { (Star-CCM+) }\end{array}$ & $\begin{array}{c}\text { CFD } \\
\text { (OpenFOAM) }\end{array}$ \\
\hline$Z_{u u}{ }^{\prime}$ & 0.0481 & 0.0590 & 0.0667 \\
$Z_{u w}{ }^{\prime}$ & 0.6429 & 0.7064 & 0.6931 \\
$Z_{w w}{ }^{\prime}$ & 0.4251 & 0.4899 & 0.1893 \\
$Z_{w|w|}{ }^{\prime}$ & 2.3354 & 2.7201 & 2.9859 \\
\hline
\end{tabular}

As shown in Figs. 13 and 14, the heave force occurred at a drift angle of $0^{\circ}$, and was not symmetrical with respect to the positive and negative directions of the drift angle. This is attributable to, based on the model test results alone, the lift caused by the top-bottom asymmetry of the hull of the model vehicle, as shown in Fig. 10(b).

Analyzing the maneuvering hydrodynamic derivatives obtained from the experimental and CFD calculation results shown in Tables 11 and 12 , although the hydrodynamic derivatives obtained from the Star-CCM+ calculation results slightly differed from those obtained from the experimental results, they are still quite similar, as in the case of the maneuvering hydrodynamic derivatives obtained for the surge force. Similarly, as the maneuvering hydrodynamic derivatives from the OpenFOAM results shown in Table 12 were calculated only under some conditions, the result for $Z_{w w}{ }^{\prime}$ was different from the experimental and Star-CCM+ results, while those for the other hydrodynamic derivatives agreed well.

For a detailed examination of the result of the heave force according to the drift angle, as shown in Fig. 11, the vertical force acting on each part of the vehicle was calculated as for the surge force. Table 13 shows the numerical values for the calculation results at drift angles of $+20^{\circ}$ and $-20^{\circ}$. According to the calculation results, disregarding the sign due to the difference in direction, such as the positive or negative direction (that is, analyzing the absolute value of the acting hydrodynamic force), heave forces of similar size acted on the horizontal wings and the hull. However, this result is different from the abovementioned statement that the left-right asymmetry of the heave force generated at a drift angle of $0^{\circ}$ results from the lift generated by the top-bottom asymmetry of the hull. In other words, the lift caused by the top-bottom asymmetry of the hull is judged to be the cause of the left-right asymmetry, based on the model test results shown in Figs. 13 and 14. However, the CFD calculation suggests that the direction of the force acting on the vertical

Table 13 Comparison of static drift test heave force acting on Manta-type UUV's each component at $V m=0.32 \mathrm{~m} / \mathrm{s}$

\begin{tabular}{ccc}
\hline Component & $F y(\mathrm{~N})\left(\Psi=20^{\circ}\right)$ & $F y(\mathrm{~N})\left(\Psi=-20^{\circ}\right)$ \\
\hline Hull & -21.490 & 20.597 \\
Left wing & -0.966 & 1.646 \\
Right wing & -1.041 & 1.748 \\
Vertical wing & -6.617 & 6.647 \\
Total & -16.880 & 30.616 \\
\hline
\end{tabular}

wing plays a greater role than the top-bottom asymmetry of the hull, regardless of the direction of the drift angle.

\subsubsection{Pitch moment}

Finally, Figs. 15 and 16 show that the pitch moment has an asymmetrical curve as the heave force forms an asymmetrical curve according the drift angle.

Similar to the cases of the surge and heave forces, the dimensionless results of the model test and CFD calculation for the pitch moment are shown, which are the results of curve fitting performed using the least-squares method and Eq. (3). The relevant hydrodynamic derivatives obtained from the results are shown in Tables 14 and 15.

While the results of the calculated hydrodynamic derivatives show a similar tendency to those of the heave force, the result of the third term, $M_{w|w|}{ }^{\prime}$, shows a huge difference as the value of the pitch moment is much smaller than that of the heave force in terms of the size of the hydrodynamic force. In addition, as the hydrodynamic derivatives obtained from the OpenFOAM results shown in Table 15 are calculated only under some conditions, the result for $M_{w w}{ }^{\prime}$ is considerably different from the experimental and Star-CCM+ results, while the results for other hydrodynamic derivatives are in good agreement.

$$
M^{\prime}=M_{u u}{ }^{\prime} u^{\prime 2}+M_{u w}{ }^{\prime} u^{\prime} w^{\prime}+M_{w w}{ }^{\prime} w^{\prime 2}+M_{w|w|}{ }^{\prime} w^{3}
$$

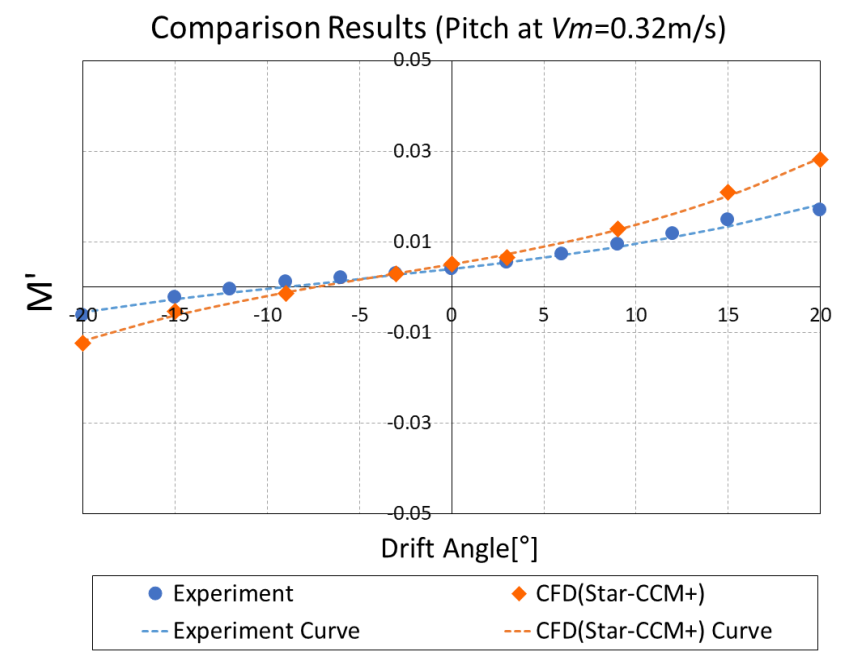

Fig. 15 Comparison of pitch moment acting on Manta-type UUV between the experiment and CFD calculation at $V m=0.32 \mathrm{~m} / \mathrm{s}$

Table 14 Comparison of hydrodynamic derivatives obtained from the pitch moment acting on Manta-type UUV between the experiment and CFD calculation at $V m=0.32 \mathrm{~m} / \mathrm{s}$

\begin{tabular}{ccc}
\hline $\begin{array}{c}\text { Hydrodynamic } \\
\text { derivatives }\end{array}$ & Experiment & CFD (Star-CCM+) \\
\hline$M_{u u}{ }^{\prime}$ & 0.0040 & 0.0051 \\
$M_{u w}{ }^{\prime}$ & 0.0265 & 0.0404 \\
$M_{w w}{ }^{\prime}$ & 0.0244 & 0.0331 \\
$M_{w|w|}{ }^{\prime}$ & 0.0837 & 0.1813 \\
\hline
\end{tabular}




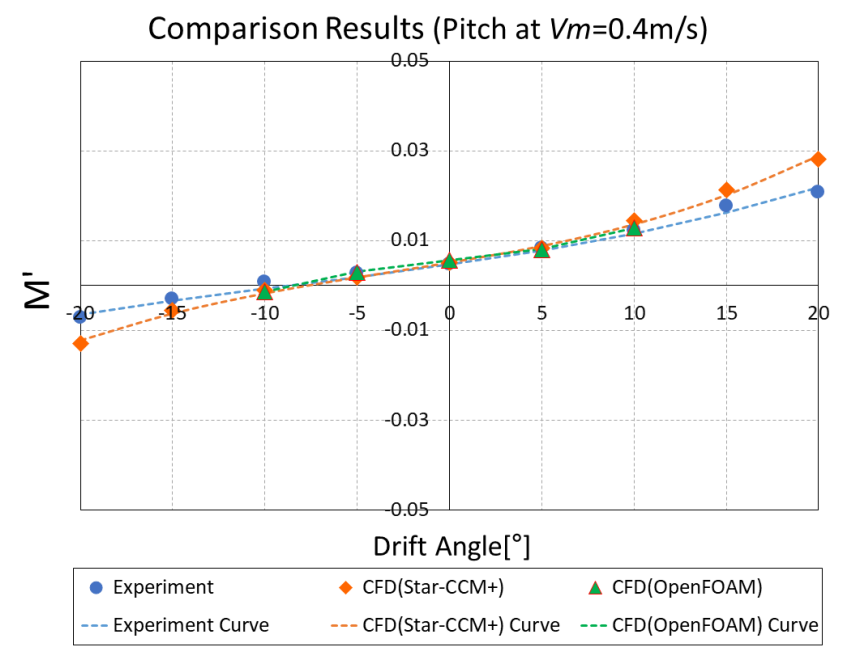

Fig. 16 Comparison of pitch moment acting on Manta-type UUV between the experiment and CFD calculation at $\mathrm{Vm}=0.4 \mathrm{~m} / \mathrm{s}$

Table 15 Comparison of hydrodynamic derivatives obtained from the pitch moment acting on Manta-type UUV between the experiment and CFD calculation at $V m=0.4 \mathrm{~m} / \mathrm{s}$

\begin{tabular}{cccc}
\hline $\begin{array}{c}\text { Hydrodynamic } \\
\text { derivatives }\end{array}$ & Experiment & $\begin{array}{c}\text { CFD } \\
\text { (Star-CCM+) }\end{array}$ & $\begin{array}{c}\text { CFD } \\
\text { (OpenFOAM) }\end{array}$ \\
\hline$M_{u u}{ }^{\prime}$ & 0.0046 & 0.0051 & 0.0055 \\
$M_{u w}{ }^{\prime}$ & 0.0333 & 0.0387 & 0.0250 \\
$M_{w w}{ }^{\prime}$ & 0.0307 & 0.0326 & 0.0091 \\
$M_{w|w|}{ }^{\prime}$ & 0.0857 & 0.2028 & 0.5421 \\
\hline
\end{tabular}

\section{Conclusion}

The results of this study - conducted to determine the hydrodynamic forces, such as the surge force, heave force, and pitch moment, which act on a Manta-type UUV in longitudinal motion through model testing and CFD analysis - are described as follows.

(1) The model test and CFD results showed a similar tendency for resistance by velocity.

(2) In the static drift test, as a result of obtaining the hydrodynamic forces from each part of the Manta-type UUV model in CFD, the surge force acting on the hull, excluding the wings, changed depending on the direction of the drift angle, showing an asymmetric tendency. In addition, for the heave force and pitch moment, the same heave force acted on the vertical wing regardless of the direction of the drift angle, and the heave force and pitch moment occurred at a drift angle of $0^{\circ}$.

(3) The model test and CFD analysis were conducted simultaneously, and the study was conducted without knowing the results. As shown in the results, the differences between the results obtained by different CFD solvers were rather insignificant and mutually reliable.
As mentioned in the Introduction, this study provides a good example for the usefulness of CFD in predicting the maneuvering performance in the initial stage of designing underwater vehicles. Nevertheless, as the model test and CFD analysis results showed a slight difference at a diagonal angle under certain conditions, further study is required to increase the accuracy of the CRD analysis. However, using CFD in combination with model testing would be beneficial in identifying the trends in hydrodynamic forces, which are difficult to be judged through model testing alone.

\section{Acknowledgments}

This research is a part of the research project which is funded by the Basic Science Research Program through the National Research Foundation of Korea (NRF) and funded by the Ministry of Education (NRF-2017R1D1A3B03030423).

\section{References}

Ko, S.H., Kim, D.H., \& Kim, J.Y. (2013). Implementation and Field Test for Atonomous Nigation for Mnta UUV. Jornal of the Korean Society of Marine Engineering, 37(6), 644-652. https://doi.org/ 10.5916/jkosme.2013.37.6.644

Bae, J.Y., \& Sohn, K.H. (2009). A Sudy on Manoeuvring Motion Characteristics of Manta-type Unmanned Undersea Vehicle. Journal of the Society of Naval Architects of Korea, 46(2), 114-126. https://doi.org/10.3744/SNAK.2009.46.2.114

Cheon, K.H., Park, J.Y., Seok, W.C., \& Rhee, S.H. (2018). Prediction of Hyrodynamic Derivatives to Estimate Manoeuvrability of A Submersible Body Using SNUFOAM. Proceedings of Korean Society for Computational Fluids Engineering Conference, 169-170. Retrieved June 2020 from http://www.dbpia.co.kr/ pdf/pdfView.do?nodeId=NODE07438390

Singh, Y., Bhattacharyya, S.K., \& Idichandy, V.G. (2017). CFD Approach to Modelling, Hydrodynamic Analysis and Motion Characteristics of a Laboratory Underwater Glider with Experimental Results. Journal of Ocean Engineering and Science, 2(2), 90-119. https://doi.org/10.1016/j.joes.2017.03.003

\section{Author ORCIDs}

$\begin{array}{ll}\text { Author name } & \text { ORCID } \\ \text { Lee, Seong-Eun } & 0000-0003-1633-2387 \\ \text { Lee, Sung-Wook } & 0000-0001-6089-303 X \\ \text { Bae, Jung-Young } & 0000-0001-7869-5330\end{array}$

